\title{
Flock differences in the impact of maternal dietary restriction on offspring growth and glucose tolerance in female offspring
}

\author{
BE Burt ${ }^{1,2}$, BW Hess ${ }^{1,2}$, PW Nathanielsz ${ }^{1,3}$ and SP Ford ${ }^{1,2}$ \\ 'The Center for the Study of Fetal Programming, Laramie, WY 82071, 2 Department of Animal Science, \\ University of Wyoming, Laramie, WY 82071; ${ }^{3}$ Department of Obstelrics and Gynecology, University \\ of Texas Health Sciences Center, San Antonio, TX 78229
}

\begin{abstract}
Variable impacts of in-utero programming stimuli on postnatal offspring development suggest that genotype may play a role in this response. In this study, ewes from two flocks of similar breeding but adapted for 6-8 generations to one of two markedly different production environments were utilized (Baggs ewes - nomadic lifestyle and limited nutrition; UW ewes - sedentary lifestyle and adequate nutrition). Ewes from each flock were fed $50 \%$ (nutrient restricted) or $100 \%$ (control) National Research Council (NRC) requirements between day 28 and 78 of gestation; some ewes in each dietary group were then necropsied. Remaining ewes were fed $100 \%$ NRC requirements from day 79 to term. Weights of singleton female fetuses were reduced $(P<0.05)$ in nutrient restricted UW ewes compared to control UW ewes on day 78. Two month old ewe lambs from nutrient restricted UW ewes had greater $(P<0.05)$ baseline glucose concentrations, and exhibited greater $(P<0.05)$ glucose and insulin concentrations to an intravenous glucose bolus than lambs from control UW ewes. From 4 to 12 months of age, ewe lambs from nutrient restricted UW ewes were heavier $(P<0.05)$ than lambs from control UW ewes. In contrast, no differences in fetal weight, baseline glucose, glucose and insulin concentration to an intravenous glucose bolus, or body weight were observed for nutrient restricted and control Baggs ewes. These data suggest that a multigenerational adaptation of ewes to different production systems impacts their ability to protect their fetus against a bout of early to mid-gestational nutrient restriction.
\end{abstract}

\section{Introduction}

Significant data has accumulated in recent years establishing an association between suboptimal intrauterine and post-natal environments and the development of adult diseases including coronary heart disease, hypertension, stroke, type II diabetes and dyslipidemia and neurologic disorders (Barker and Osmond 1988; Barker et al. 1989; Barker 1998; Gluckman and Hanson 2004). These observations have been confirmed in numerous animal studies across multiple species (Moss et al. 2001; Bertram and Hanson 2001; Mathews et al. 2002; Gluckman and Hanson 2004).

Corresponding author E-mail: spford@uwyo.edu 
Recently, Vonnahme et al. (2006) reported that Rambouillet/Columbia cross ewes from the same two flocks as utilized in this study and subjected to the same nutrient restriction, exhibited flock specific differences in placentomal growth, development, and efficiency in response to maternal nutrient restriction from early to mid-gestation. Specifically, Vonnahme et al. (2006) reported that in ewes adapted to harsh range conditions and limited nutrient availability (Baggs ewes), placentomes advanced from type A to more efficient types B, C, and D by day 78 of gestation. Further, this placentomal conversion by Baggs ewes in the face of a bout of undernutrition was shown to support normal fetal growth and maintain fetal blood glucose and amino acid concentrations at normal levels (Wu et al. 2005). Conversely, ewes not accustomed to a harsh environment or to periods of nutrient restriction (UW ewes) failed to convert type $A$ placentomes to types B, C, and D by day 78 and exhibited decreased fetal blood glucose and intrauterine growth restriction (IUGR; Vonnahme et al. 2006). In addition, Kwon et al. (2004) reported that essential amino acids were markedly reduced in the blood of these nutrient restricted UW ewes when compared to UW ewes fed to requirement. Classification of placentomal type is based on the scheme of Vatnick et al. (1991) and depends on placentome appearance as follows: 1) caruncular tissue completely surrounding the cotyledonary tissue (type A), 2) cotyledonary tissue beginning to grow over the surrounding caruncular tissue (type B), 3) flat placentomes with caruncular tissue on one surface and cotyledonary tissue on the other (type C), and 4) everted placentomes resembling bovine placentomes (type D). As placentomes progress from type A through type D, they increase in size, and exhibit a greater capillary volume and arteriolar density (Ford et al. 2004), resulting in increased placentomal blood flow (Ford et al. 2006). This adaptive mechanism among different but genetically similar, populations could provide valuable insight as to the etiology of the metabolic syndrome $X$. This syndrome is linked to IUGR and is marked by glucose tolerance, insulin resistence, obesity and hypertension, predisposing an individual to cardiovascular disease in later life (Latini et al. 2004; Reaven 2005).

Maternal undernutrition has been shown to induce insulin resistance (a precursor to type II diabetes mellitus) in a variety of species including the rat, sheep, and human (Fowden and Hill 2001; and Schwitzgebel 2001; Simmons et al. 2001). The goal of this project was to compare growth patterns and insulin and glucose responses of singleton female lambs born to nutrient restricted and control Baggs and UW ewes to a glucose challenge.

\section{Methods}

Animals

All animal procedures were approved by the University of Wyoming Animal Care and Use Committee. Ewes of similar breeding (Rambouillet/Columbia cross), age (4-5 years old) and parity (2-3 lamb crops) were obtained from two different flocks for use in this study. The first flock located near Baggs, Wyoming was adapted over 6-8 generations ( $~ 30$ years) to a nomadic existence, grazing a land mass of $\sim 250$ miles/year which ranged from desert terrain to high mountain pastures with very limited nutritional supplementation (Baggs ewes). The second flock was also maintained for 6-8 generations ( 30 years) by the University of Wyoming, and in contrast to the Baggs ewes, had a relatively sedentary lifestyle and consumed a diet from birth that always met or exceeded their dietary requirements (UW ewes). Over the course of two years, 60 Baggs ewes and 60 UW ewes were utilized for this study.

Ewes were checked for estrus twice daily and bred to an intact ram of the same breeding as the ewes at first exhibition of estrus and $12 \mathrm{~h}$ later (first day of mating $=$ day 0 ). Animals were 
fed alfalfa hay at a rate of $\sim 2 \%$ of their estimated body weight from 60 days before mating to day 20 post-mating. On day 20 post-mating, ewes were weighed so that individual diets could be provided on a metabolic body weight basis (body weight ${ }^{0.75}$ ). The control ration consisted of a pelleted beet pulp (93.5\% dry matter [DM], 79\% total digestible nutrients [TDN], and $10.0 \%$ crude protein). Daily rations were delivered on a DM basis to meet the TDN required for maintenance of a pregnant ewe (NRC, 1985). A mineral-vitamin mixture $(51.43 \%$ sodium triphosphate, $47.62 \%$ potassium chloride, $0.39 \%$ zinc oxide, $0.06 \%$ cobalt acetate, and $0.50 \%$ ADE vitamin premix [8,000,000 IU vitamin A, 800,000 IU vitamin D3, and 400,000 IU vitamin E per pound; amount of vitamin premix was formulated to meet the vitamin A requirements]) was included with the beet pulp pellets to meet requirements. On day 21 post-mating, all UW and Baggs ewes were placed in individual pens and fed the control diet satisfying $100 \%$ of NRC requirements for the early gestational ewe (NRC 1985). On day 28 post-mating, ewes within each flock were randomly assigned in equal numbers to either remain on the control diet at $100 \%$ NRC requirements (control) or were fed the control diet at $50 \%$ NRC requirements (nutrient restricted). On day 45 post-mating, pregnancy was confirmed by ultrasonography (Ausonics Microimager 1000 sector scanning instrument; Ausonics Pty Ltd, Sydney, Australia). At weekly intervals from day 28 of gestation until parturition, all ewes were weighed and daily rations adjusted for body weight gain for control or loss for nutrient restricted. On day 79 of gestation, 10 ewes in each of the four treatment groups carrying singleton pregnancies were necropsied and fetal weight and crown rump lengths were determined for female fetuses. All remaining nutrient restricted UW and Baggs ewes were re-alimented to the control diet on day 79 , and thereafter all remaining ewes from both flocks were fed to meet NRC requirements for the early gestational ewe (NRC 1985) until day 104 of gestation. From day 105 of gestation until the day of parturition, the rations fed to all pregnant ewes were increased according to NRC guidelines for late gestational ewes (NRC 1985).

\section{Parturition and postnalal procedures}

Lambing was allowed to proceed naturally in all ewes, which were given free choice access to good quality alfalfa hay thereafter. Immediately after birth, lambs were towel dried and morphometric data (birth weight, crown-rump length, abdominal and thoracic circumferences, biparietal diameter, and right and left humerus lengths) were collected and recorded for all singleton ewe lambs. Singleton ewe lambs born to each of 8 control UW ewes and 7 control Baggs ewes, as well as 7 nutrient restricted UW and 8 nutrient restricted Baggs ewes were selected for inclusion in this study to avoid potential differences due to pregnancy status (singleton and twin). Prior to 14 days of age, ewe lambs were tail-docked as per Federation of Animal Science Societies recommendations (FASS 1999). All lambs were given free access to a standard commercially available creep feed (Lamb Creep B30 w/Bovatec; Ranch-Way Feeds, Ft. Collins, CO) from birth to weaning. At $120 \pm 2$ days of age, ewe lambs were weaned and placed in an outdoor housing facility with shelter and ad libitum water. Lambs were fed a diet formulated to maintain a daily gain of $0.23 \mathrm{~kg}$ according to NRC requirements for replacement ewes (NRC 1985). The diet consisted of a $65 \%$ alfalfa hay and $35 \%$ corn mixture. In order to satisfy NRC phorphorus requirements, the corn mixture was fortified with sodium triphosphate mineral mix such that $99.25 \%$ of the mixture was corn and $0.75 \%$ was sodium triphosphate. Lambs were fed this diet until 8 months of age at which time they were switched to a diet consisting of ad libitum access to an alfalfa hay diet. 
Glucose Tolerance Test (GTT)

All selected singleton ewe lambs were removed from their mothers at $63 \pm 1$ days of lactation, for a $12 \mathrm{~h}$ period, then weighed and jugular veins were catheterized without anesthesia (Terumo ${ }^{\circledR}$ Surflash 18 gauge x 2.5 inches long, Ann Arbor, MI), and using aseptic procedures. Lambs were allowed approximately 60 min to recover before initiating a glucose tolerance test. At -15 and -5 min before administration of a bolus injection of glucose $(0.25 \mathrm{~g} / \mathrm{kg}$ of body weight in $20 \mathrm{~s}, 50 \%$ dextrose solution; Vedco; St. Joseph, MO), $5 \mathrm{~mL}$ blood samples were drawn from the venous catheter and $2 \mathrm{~mL}$ placed into tubes containing heparin and sodium fluoride $(2.5 \mathrm{mg} / \mathrm{mL}$; Sigma) and the remaining $3 \mathrm{~mL}$ placed into a vacutainer tube with no anticoagulant (5mL; Sigma, St. Louis, MO) to establish baseline values of glucose and insulin, respectively. Additional blood samples were collected at 2, 5, 10,15,30,60, and 120 min after glucose injection. Catheters were flushed with heparinized saline following glucose infusion and after each blood sampling. Heparinized blood samples were stored on ice until centrifuged at $3000 \times \mathrm{g}$ for $10 \mathrm{~min}$, and plasma stored at $-80^{\circ} \mathrm{C}$ until analysis; while the nonheparinized samples were allowed to clot for $24 \mathrm{~h}$ at $4^{\circ} \mathrm{C}$ before centrifugation at $3000 \times \mathrm{g}$ for $10 \mathrm{~min}$, and serum stored at $-80^{\circ} \mathrm{C}$ until subsequent analysis.

\section{Hormone assays}

Glucose was analyzed using the Infinity ${ }^{\top M}$ (ThermoTrace Ltd, Cat. \# TR15498; Melbourne, Australia) colorimetric assay modified in the following manner; plasma was diluted $1: 5$ in $\mathrm{dH}_{2} \mathrm{O}$, and $10 \mu \mathrm{L}$ of diluted plasma was added to $300 \mu \mathrm{L}$ reagent mix. All samples were run in triplicate, and sample analysis was completed using multiple assays. The intra-assay and inter-assay CVs were $5 \%$ and $7 \%$, respectively. Insulin was measured by RIA in accordance with manufacturer recommendations (Coat-A-Count ${ }^{\circledR}$, Diagnostic Products Corporation, Los Angeles, CA) and completed using two assays. The intra-assay CV was $<5 \%$, while the inter-assay CV was $<3 \%$. Fasted glucose and insulin baseline values were ascertained from the -15 and -5 min samples.

\section{Calculations and statistics}

All data are presented as means \pm SEM and significance was accepted when $\mathrm{P}<0.05$, with $\mathrm{P}<$ 0.10 considered a trend. Area under the curve (AUC) was determined for insulin and glucose using the trapezoidal rule with GraphPad Prism software (Version 3, GraphPad). Weight gain was calculated as the change in body weight between two consecutive measurements. Statistical comparisons between groups (nutrient restricted vs. control) were completed using independent t-test, split-plot ANOVA where appropriate (SAS V8.2, SAS Inst. Inc., Cary, NC). Post hoc analysis was performed as indicated with a LSD test.

\section{Results}

\section{Maternal and fetal data}

On day 28 of gestation, body weights of Baggs and UW ewes were similar averaging $75.23 \pm$ $3.05 \mathrm{~kg}$. At the end of the treatment period on day 78 of gestation, control Baggs and UW ewes had increased $7.21 \pm 0.70 \%$ in body weight, while nutrient restricted Baggs and UW ewes had lost $8.32 \pm 0.51 \%$ of their day 28 weight. Weights and crown rump lengths of day 78 singleton 
fetuses from nutrient restricted UW ewes were reduced $(P<0.05)$ when compared to those of control UW ewes and nutrient restricted and control Baggs ewes which were similar (Table 1). At term, control and nutrient restricted-realimented Baggs and UW ewes reached similar weights averaging $94.04 \pm 4.20 \mathrm{~kg}$.

Table 1. Body weight (BWT) and crown rump length (CRL) of singleton female feluses on day 78 of gestation in nutrient restricted and control UW and Baggs ewes.

\begin{tabular}{lcccc}
\hline Measurements & $\begin{array}{c}\text { UW control } \\
\text { lambs } \\
(n=5)\end{array}$ & $\begin{array}{c}\text { UW nutrient } \\
\text { restricted lambs } \\
(n=4)\end{array}$ & $\begin{array}{c}\text { Baggs control } \\
\text { lambs } \\
(n=4)\end{array}$ & $\begin{array}{c}\text { Baggs nutrient } \\
\text { restricted lambs } \\
(n=5)\end{array}$ \\
\hline BWT (g) & $301 \pm 11^{\text {a }}$ & $225 \pm 7^{\text {b }}$ & $294 \pm 9^{a}$ & $289 \pm 12^{\text {a }}$ \\
CRL (cm) & $22.8 \pm 0.4^{\text {a }}$ & $20.1 \pm 0.4^{\text {b }}$ & $22.4 \pm 0.5^{a}$ & $22.2^{\text {a }} \pm 0.6^{\text {a }}$ \\
\hline
\end{tabular}

Values are expressed as the mean \pm SEM. Values with different superscripts differ $(P<0.05$ ).

Neonatal morphometric data and postnatal growth

No differences were observed at birth in the lambs from nutrient restricted and control Baggs ewes for any of the morphometric measurements taken (Table 2). In contrast, while the lambs from nutrient restricted and control UW ewes showed no differences in birth weight $(5.2 \pm 0.3$ vs. $5.4 \pm 0.2 \mathrm{~kg} ; \mathrm{P}>0.05)$, abdominal girth was reduced $(\mathrm{P}<0.05)$ and thoracic girth tended to be reduced $(\mathrm{P}<0.10)$ in offspring from nutrient restricted UW ewes when compared to offspring from control UW ewes.

Table 2. Neonatal morphometric data taken immediately after birth and prior to the first nursing of singleton female lambs.

\begin{tabular}{|c|c|c|c|c|}
\hline & UW Control & UW NR & Baggs Control & Baggs NR \\
\hline CRL $(\mathrm{cm})$ & $55.5 \pm 0.9^{a}$ & $57.3 \pm 0.9^{a}$ & $56.1 \pm 0.8^{\circ}$ & $57.7 \pm 0.8^{\circ}$ \\
\hline $\mathrm{BPD}(\mathrm{cm})$ & $17.1 \pm 0.5^{\mathrm{a}}$ & $16.7 \pm 0.5^{a}$ & $18.8 \pm 0.8^{a}$ & $19.5 \pm 0.5^{a}$ \\
\hline RHL (cm) & $15.5 \pm 0.3^{\circ}$ & $15.5 \pm 0.2^{\mathrm{a}}$ & $16.4 \pm 0.9^{\circ}$ & $16.7 \pm 0.3^{a}$ \\
\hline LHL (cm) & $15.8 \pm 0.2^{\mathrm{a}}$ & $15.5 \pm 0.2^{\mathrm{a}}$ & $16.5 \pm 0.9^{\alpha}$ & $16.9 \pm 0.3^{\circ}$ \\
\hline $\mathrm{TG}(\mathrm{cm})$ & $41.2 \pm 0.5^{a}$ & $39.9 \pm 0.6$ & $42.2 \pm 1.3^{\circ}$ & $43.0 \pm 0.5^{\circ}$ \\
\hline $\mathrm{AG}(\mathrm{cm})$ & $39.4 \pm 0.6^{a}$ & $37.0 \pm 0.7^{b}$ & $40.0 \pm 0.8^{\circ}$ & $42.2 \pm 1.0^{4}$ \\
\hline BWT (kg) & $5.2 \pm 0.2^{a}$ & $5.4 \pm 0.2^{3}$ & $5.9 \pm 0.6^{4}$ & $5.8 \pm 0.39$ \\
\hline
\end{tabular}

Mean \pm SEM with different superscripts differ $(P<0.05)$. ${ }^{*}$ Mean \pm SEM differ $(P<0.10)$.

Morphometric measurements: crown rump length (CRL); bi-parietal diameter (BPD); right humerus length (RHL); left humerus length (LHL); thoracic girth (TG); abdominal girth (AG); birth weight (BWT).

There was no difference in the weights of ewe lambs from nutrient restricted and control Baggs ewes from birth to one year of age (Fig. 1). In contrast, by four months of age UW lambs from nutrient restricted UW ewes were heavier ( $P<0.05$; Fig. 2) than lambs from control UW ewes, and these lambs remained heavier $(P<0.05)$ than lambs from control UW ewes until weighing ceased at one year of age. 


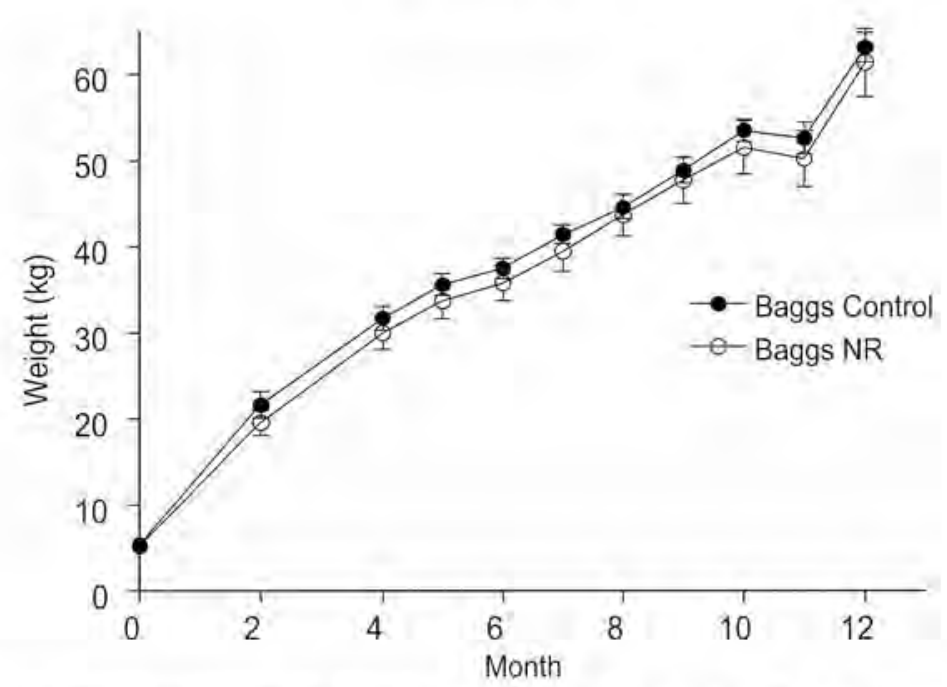

Fig. 1. Body weight response in female lambs born to Baggs ewes fed to satisfy requirements throughout gestation $(\bullet, n=7)$ and to ewes fed $50 \%$ of requirements between day 28 through day 78 of gestation then fed to satisfy requirements thereafter $(0, n=8)$. Values are expressed as mean \pm SEM.

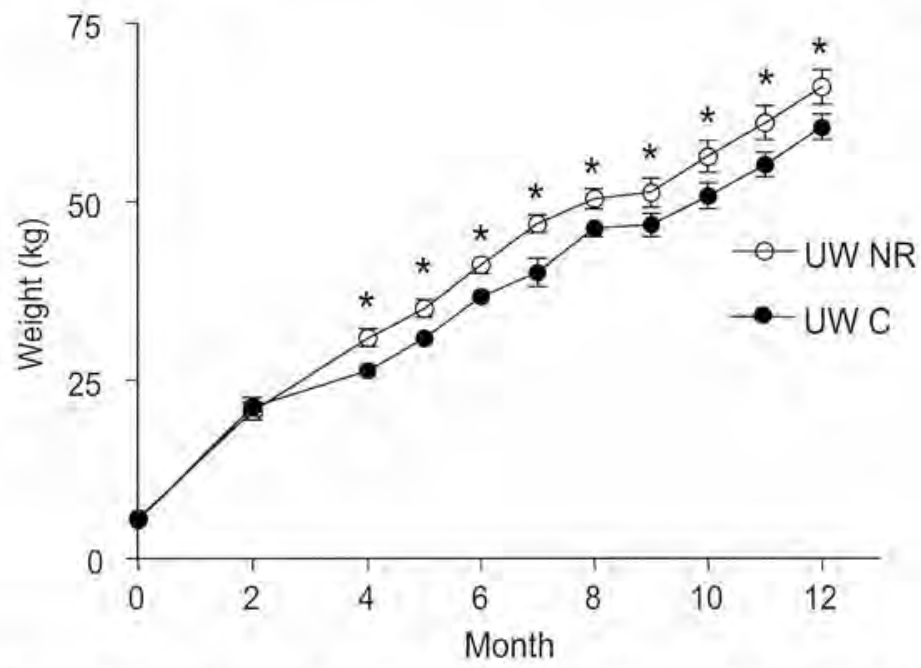

Fig. 2. Body weight response in female lambs born to $U W$ ewes fed to satisfy requirements throughout gestation $(\bullet, n=8$ ) and to ewes fed $50 \%$ of requirements between day 28 through day 78 of gestation then fed to satisfy requirements thereafter $(0, n=7)$. Astericks indicate significant differences $(P<0.05)$. Values are expressed as mean \pm SEM.

\section{Two month glucose tolerance test}

Baseline glucose levels in systemic blood averaged $82.4 \pm 8.1 \mathrm{mg} / \mathrm{dL}$ for lambs of nutrient restricted Baggs ewes and $76.8 \pm 7.2 \mathrm{mg} / \mathrm{dL}$ for lambs from control Baggs ewes, which were similar. In contrast, lambs from nutrient restricted UW ewes had higher $(P<0.05)$ average 
baseline glucose concentrations than lambs from control UW ewes which averaged $90.7 \pm 4.8$ $\mathrm{mg} / \mathrm{dL}$ and $71.3 \pm 4.0 \mathrm{mg} / \mathrm{dL}$, respectively. Peak glucose concentrations were attained at two min following the administration of the glucose bolus in lambs from all Baggs and UW ewes regardless of dietary group (Figs. 3 and 4). Peak concentrations of glucose in the offspring of control and nutrient restricted Baggs ewes averaged $226.64 \pm 15.86 \mathrm{mg} / \mathrm{dL}$ and $243.4241 \pm$ $15.25858 \mathrm{mg} / \mathrm{dL}$ respectively, which did not differ (Fig. 3). Similarly, no treatment differences in glucose concentration were observed throughout the remainder of the glucose response curve in Baggs lambs. In contrast, peak glucose concentrations of lambs from nutrient restricted UW offspring reached higher concentrations $(P<0.05)$ than those of lambs from control UW ewes which averaged $251.98 \pm 22.52 \mathrm{mg} / \mathrm{dL}$ and $205.64 \pm 16.15 \mathrm{mg} / \mathrm{dL}$, respectively (Fig. 4). Additionally, glucose concentrations remained higher $(P<0.05)$ in the lambs from nutrient restricted UW ewes than lambs from control UW ewes for $10 \mathrm{~min}$ after bolus administration. Further, the total area under the curve (AUC) for glucose tended $(P<0.09$ ) to be higher in the lambs from nutrient restricted UW ewes than in the lambs from control UW ewes, while no differences were observed between the two Baggs dietary groups. Glucose concentration of lambs from both control and nutrient restricted Baggs and UW ewes returned to baseline concentrations within the two hour testing period.

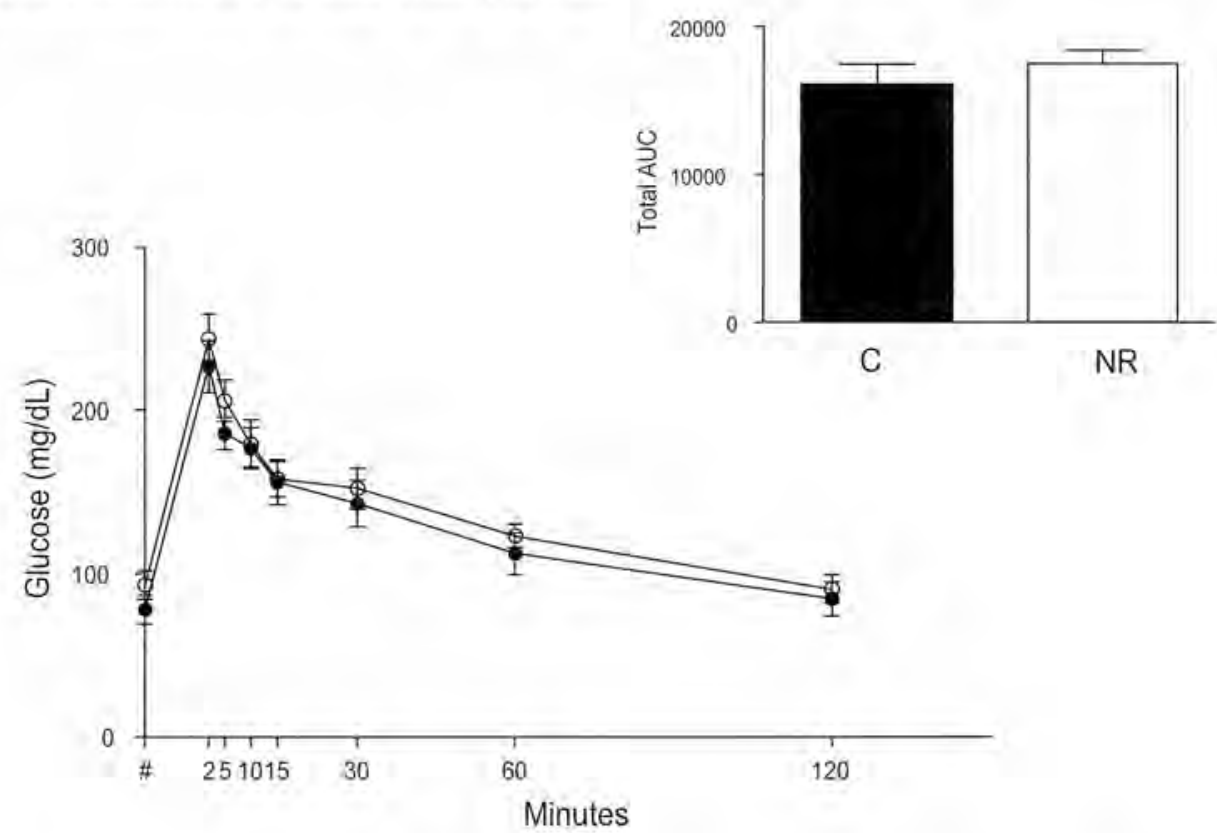

Fig. 3. Glucose concentrations before and after a glucose challenge $(0.25 \mathrm{~g} / \mathrm{kg}$ of $50 \%$ dextrose solution intravenously) at $63 \pm 1$ day of post-natal age in female lambs born to Baggs ewes fed to satisfy requirements throughout gestation $(\bullet, n-7)$ and to Baggs ewes fed $50 \%$ of requirements between d 28 through 78 of gestation then day fed to satisfy requirements thereafter $(0, n=8)$. The (\#) symbol on the $X$ axis denotes pre-injection concentrations (average of -15 and -5 time points). Area under the curve (AUC; $\mu \| \mathrm{min}^{-1}$ ) depicted in the inset. Values are expressed as mean \pm SEM.

Baseline insulin values averaged $1.29 \pm 0.23 \mathrm{pg} / \mathrm{mL}$ for the lambs from Baggs control ewes and $1.27 \pm 0.31 \mathrm{pg} / \mathrm{mL}$ for the lambs from nutrient restricted Baggs ewes, which did not differ (Fig. 5). Similarly, no significant differences were found in average baseline insulin concentrations 


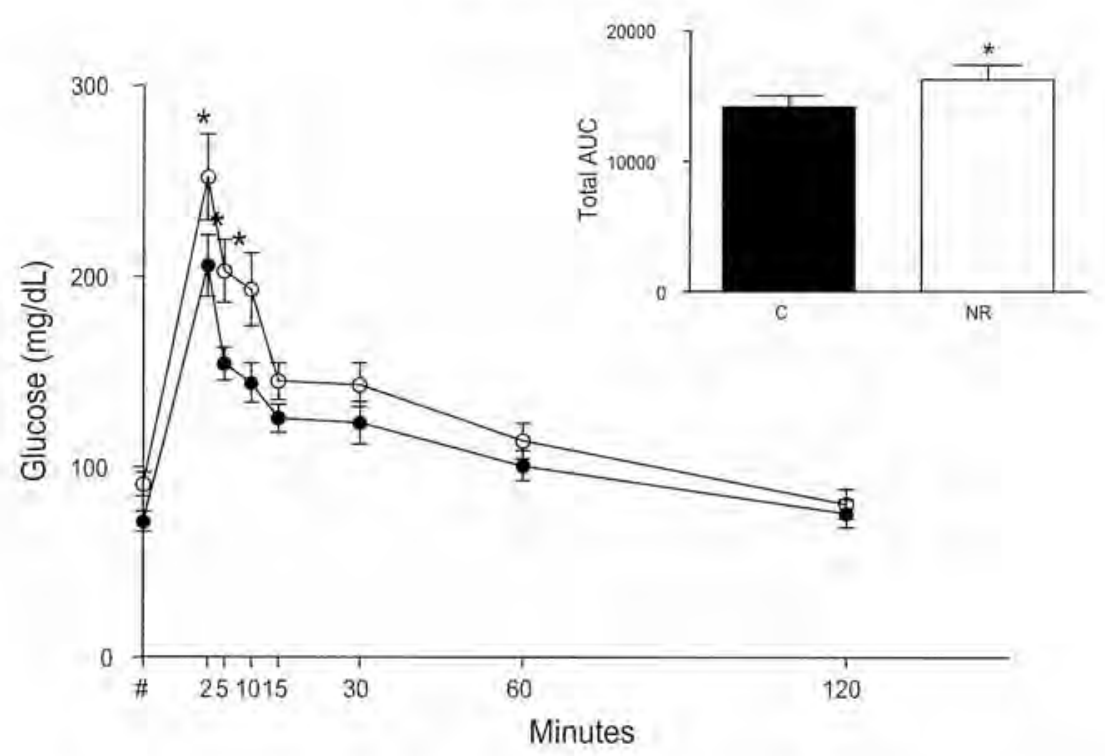

Fig. 4. Glucose concentrations before and after a glucose challenge $(0.25 \mathrm{~g} / \mathrm{kg}$ of $50 \%$ dextrose solution intravenously) at $63 \pm 1$ day of post- natal age in female lambs born to UW ewes fed to satisfy requirements throughout gestation $(\bullet, n=8)$ and to UW ewes fed $50 \%$ of requirements between d 28 through day 78 of gestation then fed to satisfy requirements thereafter $(O, n=8)$. The (\#) symbol on the $X$ axis denotes pre-injection concentrations (average of -15 and -5 time points). Area under the curve ( $A \cup C ; \mu \mathrm{IU} \mathrm{min}^{-1}$ ) depicted in the inset was greater in nutrient restricted than control fed offspring. The asterisk indicates significant difference $(\mathrm{P}<0.01)$. Values are expressed as mean \pm SEM.

between lambs from control and nutrient restricted UW ewes, which averaged $1.26 \pm 0.35 \mathrm{pg} /$ $\mathrm{mL}$ and $1.80 \pm 0.35 \mathrm{pg} / \mathrm{mL}$, respectively (Fig.e 6). Peak insulin levels were reached at five to ten minutes after glucose administration in all groups (Figs. 5 and 6). In the Baggs control lambs, peak insulin values were $17.12 \pm 4.53 \mathrm{pg} / \mathrm{mL}$, and in the nutrient restricted Baggs lambs they averaged $13.24 \pm 2.68 \mathrm{pg} / \mathrm{mL}$, but this difference was not significant $(P=0.43)$. Insulin concentrations in the blood of lambs from both control and nutrient restricted Baggs ewes had returned to baseline by $120 \mathrm{~min}$. (Fig. 5). While peak insulin values were reached at the same time interval after glucose administration in the lambs from UW ewes (Fig. 6), significant treatment differences were observed. The offspring from control UW ewes reached peak insulin values of $10.80 \pm 2.05 \mathrm{pg} / \mathrm{ml}$, while the nutrient restricted animals obtained average peak values of $18.65 \pm 4.21 \mathrm{pg} / \mathrm{mL}$, nearly double their control cohorts (Fig. $6 ; \mathrm{P}<0.05$ ). Further, insulin levels remained higher $(P<0.05)$ for $60 \mathrm{~min}$ after the glucose bolus in the lambs from nutrient restricted UW ewes when compared to lambs from control UW ewes. Again, insulin concentration of lambs from control and nutrient restricted UW ewes returned to baseline concentrations within the two hour testing period. 


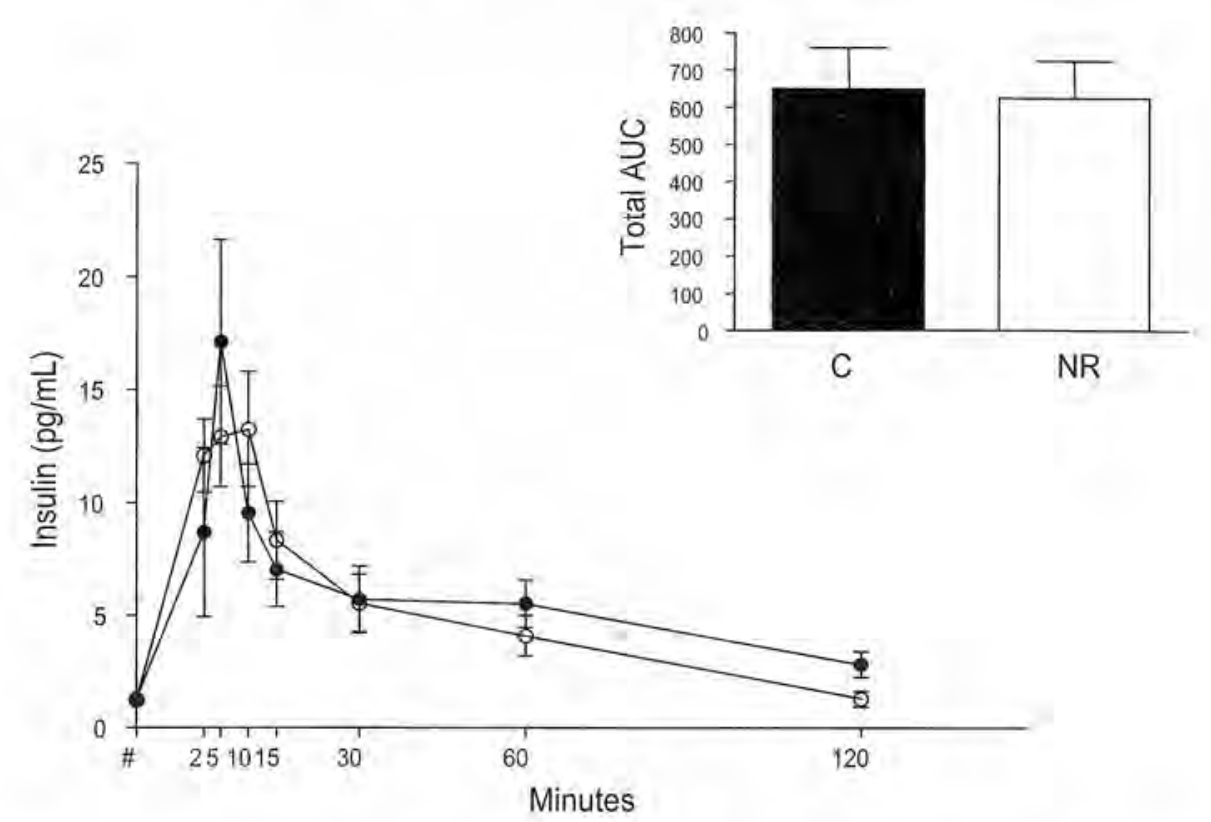

Fig. 5. Insulin concentrations before and after a glucose challenge $(0,25 \mathrm{~g} / \mathrm{kg}$ of $50 \%$ dextrose solution intravenously) at $63 \pm 1$ day of post-natal age in female lambs born to Baggs ewes fed to satisfy requirements throughout gestation $(\bullet, n-7)$ and to Baggs ewes fed $50 \%$ of requirements between d 28 through day 78 of gestation then fed to satisfy requirements thereafter $(0, n=8)$. The (\#) symbol on the $X$ axis denotes pre-injection concentrations (average of -15 and -5 time points). Area under the curve ( $A \cup C ; \mu \mathrm{IU} \mathrm{min}^{-1}$ ) depicted in the inset. Values are expressed as mean \pm SEM.

\section{Discussion}

To our knowledge, this is the first study in a livestock species demonstrating that ewes of similar breeding adapted over several generations to markedly different management systems alters the impact of maternal nutrient restriction on fetal growth as well as postnatal growth and endocrine status of their offspring. Specifically, female fetuses gestated by nutrient restricted UW ewes exhibited markedly reduced weights on day 78 of gestation when compared to female fetuses gestated by control UW ewes, while no reduction in fetal weight was observed in nutrient restricted Baggs ewes. Consistent with these findings, we have previously reported that this model of early to mid-gestational nutrient restriction results in decreased concentrations of glucose, essential amino acids and polyamines in the blood of fetuses gestated by nutrient restricted UW ewes, but not in the fetuses of nutrient restricted Baggs ewes on day 78 (Vonnahme et al. 2003; Kwon 2004; Wu et al. 2005). Much data has accrued that links IUGR to the metabolic syndrome X (Barker and Clark 1997; Latini et al. 2004; Stocker et al. 2005). The syndrome symptoms include impaired glucose and lipid metabolism, hypertension, and insulin resistance (Reaven 2005). Further, maternal undernutrition from early to mid-pregnancy in ewes has been shown to affect the hypothalamic-pituitary-adrenal axis and cardiovascular function of their lambs in the absence of altered birth weight (Hawkins et al. 2000; Gilbert et al. 2005). 


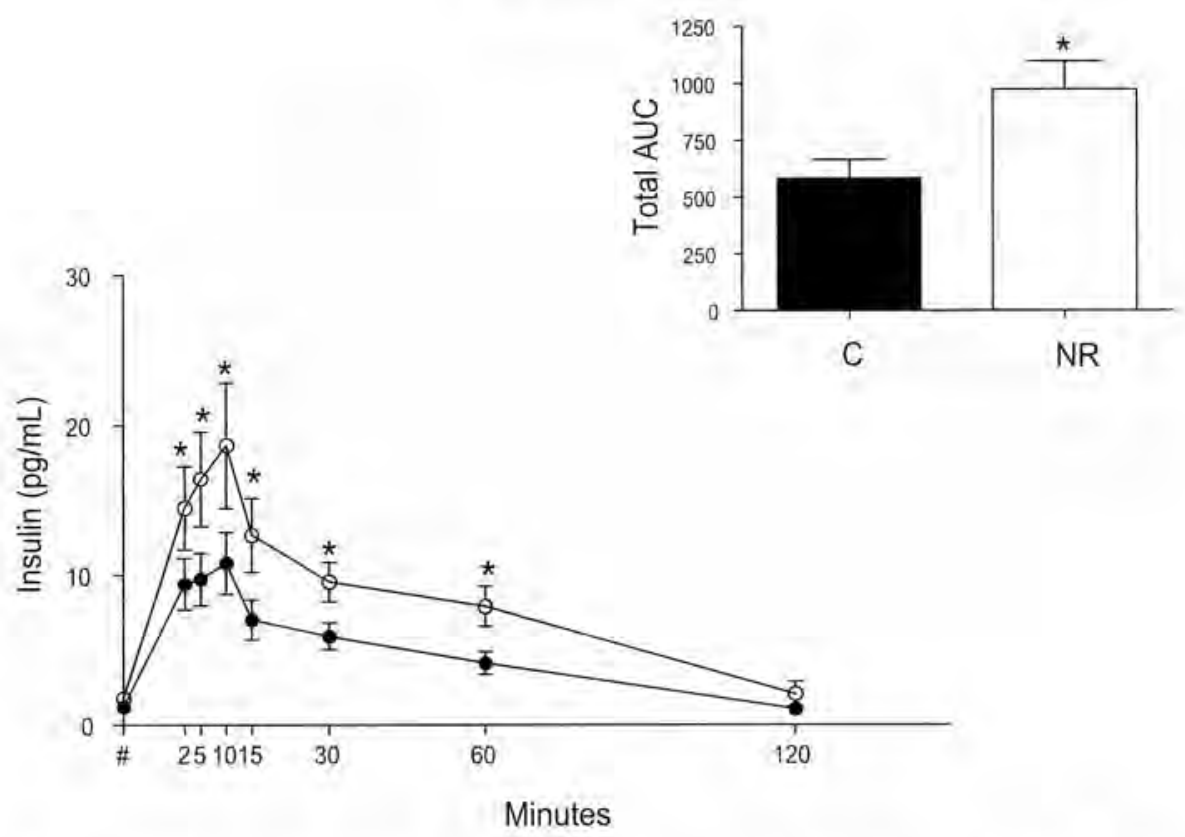

Fig. 6. Insulin concentrations before and after a glucose challenge $(0.25 \mathrm{~g} / \mathrm{kg}$ of $50 \%$ dextrose solution intravenously) at $63 \pm 1$ day of post-natal age in female lambs born to UW ewes fed to satisfy requirements throughout gestation $(\bullet, n-8)$ and to ewes fed $50 \%$ of requirements between $d 28$ through day 78 of gestation then fed to satisfy requirements thereafter $(0, n=7)$. The (\#) symbol on the $X$ axis denotes pre-injection concentrations

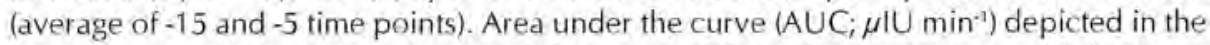
inset was greater in nutrient restricted than control fed offspring. The asterisk indicates significant difference $(P<0.05)$. Values are expressed as mean \pm SEM .

Because the weights of fetuses of nutrient restricted UW ewes were reduced compared to fetuses gestated by control UW ewes on day 78, and the weights of lambs from nutrient restricted and control UW ewes were similar at birth, an increased fetal growth rate must have occurred after realimentation in nutrient restricted UW ewes (see Fig. 7). Several studies have proposed a strong connection between IUGR, postnatal "catch-up growth" and the incidence of obesity and type 2 diabetes mellitus (Desai and Hales 1997; Bertin et al. 1999; Ericksson etal. 1999; Simmons et al. 2001; Hales and Ozanne 2003). The additional consequences, if any, of the observed pre-natal acceleration of fetal growth rate in the offspring of nutrient restrictedrealimented UW ewes observed in this study is at present unknown.

The current observations show that a significant divergence in body weight occurred between the lambs of control and nutrient restricted UW ewes but not Baggs ewes between 2 and 4 months of age. This period includes the time at which the animals were suckling and allowed free access to creep feed. While we have no measurements of actual feed consumption during this interval, it is possible that consumption of milk and or consumption of creep feed may have differed between the lambs from nutrient restricted and control UW ewes. During this period, the lambs from nutrient restricted UW ewes also demonstrated an increased insulin response measured as area under the curve to a glucose tolerance test. In response to this initial glucose tolerance test at 63 days of age (pre-weaning), the lambs from nutrient restricted UW ewes presented a reduced capacity to clear glucose from the bloodstream as well as hyper-secretion of insulin in 


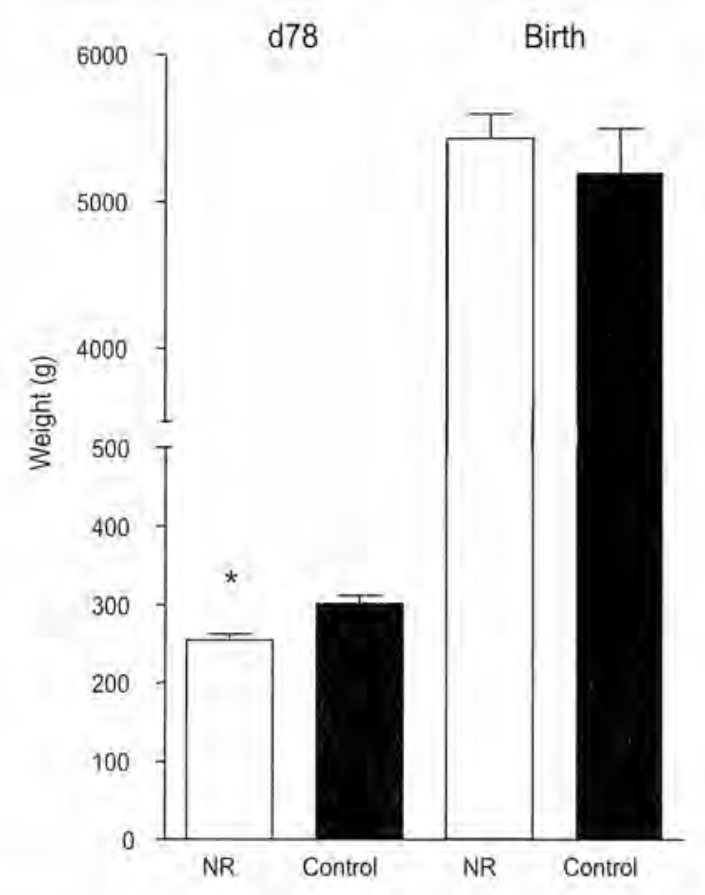

Fig. 7. Day 78 fetal weights and birth weights of lambs from nutrient restricted (NR) and control UW ewes. The asterisk indicates significant difference $(P<0.05)$. Values are expressed as mean \pm SEM.

comparison to the control UW lambs. These data suggest that maternal undernutrition during early to mid-gestation triggers a hyper-responsive pancreatic insulin secretion during the pre-weaning period in response to a glucose rise. The augmented insulin secretion that we observed during this time period may underlie the divergence in growth rate observed, as it has been demonstrated previously that insulin is a potent anabolic hormone in the growing lamb. (Wolffe et al. 1989).

As previously stated, our group has recently reported that differences in placental efficiency may mediate the fetal growth rate differences seen in nutrient restricted UW ewes versus nutrient restricted Baggs ewes (Vonnahme et al. 2006). Results from several laboratories have demonstrated an increased conversion of type A placentomes to types B, C, and D placentomes in undernourished ewes when compared to their well-fed counterparts, however, this conversion has been thought to occur only in late gestation in association with the exponentially growing fetus (Crowe et al. 1996; Hoet and Hanson 1999; Osgerby et al. 2002; Osgerby et al. 2004). The ability of nutrient restricted Baggs ewes, but not UW ewes, to increase placentomal conversion and thus the size and vascularity of placentomes in response to early to mid-gestational undernutrition, would be expected to result in increased oxygen and nutrient availability to the fetus, thus preventing IUGR and associated health problems of offspring in later life. This conclusion is consistent with data presented in this study which demonstrated that nutrient restricted UW ewes experienced IUGR, as well as increased growth rates, hyperglycemia, and insulin resistance in their female offspring. In contrast, no differences were observed in fetal growth of nutrient restricted versus control Baggs ewes, or in the growth rates, blood glucose or insulin concentrations in their female offspring. 
Simmons et al. (2001) used uterine artery ligation to induce IUGR in late gestation rats. They showed that restricted juvenile offspring developed accelerated growth rates, obesity, insulin resistance, and hyperglycemia. Further, as these restricted animals aged, insulin elevations progressively declined and animals actually experienced an inability to handle glucose. This may have been a consequence of an approximate $60 \%$ decrease in ß-cell mass and subsequent B-cell failure (Simmons et al. 2001). Heywood et al. (2004) also found that maternal protein restriction in rats decreases the glucokinase activity of pancreatic beta cells of the offspring, causing decreased glucose tolerance and possible trend towards diabetes. Using a similar model, Lopes da Costa et al. (2004) demonstrated increased insulin secretion and Glut2 transporters in pancreatic islets in young male neonatal rats. Gardner et al. (2005) reported that undernutrition ( $50 \%$ of requirements) of pregnant ewes during the last 37 days of gestation, but not during the first 30 days, resulted in glucose intolerance in the resulting offspring at 12 months of age. The impacts of periconceptional undernutrition on ovine fetal pancreatic function have also been demonstrated previously, as Oliver et al. (2001) reported that feeding 60\% of requirements from 60 days before to 30 days after conception magnified fetal insulin release to a glucose challenge in late gestation.

In the past few years, several laboratories have evaluated the impact of maternal nutrient restriction from early to mid gestation on fetal and placental development in the sheep (Clarke et al. 1998; Heasman et al. 1999; Osgerby et al. 1999 and 2002; Vonnahme et al. 2003) and have reported markedly different results. The reasons for these differences may relate to differences in ewe breed, age, or parity, but may also relate to differences in nutritional and/or environmental exposures either before or after birth or even to alterations in the epigenetic state of the fetal genome. An understanding of how the two flocks of ewes utilized in this study evolved in a relatively short time frame to be either "sensitive to feed restriction" or "resistent to feed restriction" could be critically relevant to our understanding of factors dictating nutrient requirements during gestation in livestock species. Buhimschi et al (2001) reported that the levels of hypertension, intrauterine growth restriction, and fetal death to nitric oxide inhibition during pregnancy were significantly different in the same strain of rats purchased from different commercial suppliers. These researchers concluded that these differences may represent subtle genetic or environmental differences between the two outbred colonies resulting in dramatic variations in response to nitric oxide inhibition. Further, Knight et al. (2005) reported markedly different impacts of a $30 \%$ maternal nutrient restriction from day 6.5 to 18.5 of gestation in two strains of mice on fetal and placental size and offspring growth These studies suggest that within or between breed (or strain) differences exist in the susceptability of the conceptus to a variety of maternal stressors.

\section{Conclusion}

These data suggest that multigenerational adaptation of ewes of similar breeding to differing production systems impacts their ability to protect their fetus against a bout of early to mid-gestational nutrient restriction. More specifically, ewes adapted to harsh range conditions and limited nutrient availability maintained fetal growth in the face of an early gestational nutrient restriction, thereby preventing IUGR and thus the associated health problems of their offspring in adult life. In contrast, ewes adapted to less harsh conditions, and supplied with a diet which always met or exceeded their dietary requirements, failed to maintain fetal growth in the face of a similar bout of nutrient restriction resulting in IUGR, as well as hyperglycemia, and insulin resistance in their offspring, conditions which are linked to health problems in later life. Additional research is urgently needed to gain an understanding of the physiologic basis of these adaptation-induced differences in susceptibility to gestational nutrient restriction in ruminant species. 


\section{Acknowledgements}

The authors wish to acknowledge support from University of Wyoming BRIN P20 RR16474, and INBRE P20 RR016474-04, and NIH HD 21350, and to thank Carole Hertz and Myrna Miller for laboratory and technical assistance and Reed Davidson and Mark Grant for animal care and management.

\section{References}

Barker DJ 1998 In utero programming of chronic disease. Clinical Science (London) 95 115-128.

Barker DJ \& Clark PM 1997 Fetal undernutrition and disease in later life. Reviews of Reproduction 2 105112.

Barker DJ \& Osmond C 1988 Low birth weight and hypertension. British Medical Journal 297 134-135.

Barker DJ, Winter PD, Osmond C, Margetts B \& Simmonds S) 1989 Weight in infancy and death from ischaemic heart disease. Lancet 2 577-580.

Buhimschi IA, Shi SQ, Saade GR \& Garfield RE 2001 Marked variation in response to long-term nitric oxide inhibition during pregnancy in outbred rats from two different colonies. American Journal of Obstetrics \& Gynecology 184 686-693.

Bertin E, Gangnerau MN, Bailbe D \& Portha B 1999 Glucose metabolism and beta-cell mass in adult offspring of rats protein and/or energy restricted during the last week of pregnancy. American Journal of Physiology 277 E11-E17.

Bertram CE \& Hanson MA 2001 Animal models and programming of the metabolic syndrome. British Medical Bulletin. 60 103-121.

Clarke L, Heasman L, Juniper DT \& Symonds ME 1998 Maternal nutrition in early-mid gestation and placental size in sheep. British Journal of Nutrition $\mathbf{7 9}$ 359-364.

Crowe C, Hawkins P, Saito T, Stratford LL, Noakes DA \& Hanson MA 1996 Nutritional plane in early pregnancy: effect on fetal and placental size in late gestation. Proceedings Fetal and Neonatal Physiology Society pp 11.

Desai M \& Hales CN 1997 Role of fetal and infant growth in programming metabolism in later life. Biology Review of Cambridge Philosophy Society 72 329-348.

Eriksson JG, Forsen T, Tuomilehto J, Winter PD, Osmond C \& Barker DJP 1999 Catch-up growth in childhood and death from coronary heart disease: longitudinal study. Britsih Medical Journal 318 427-431.

FASS 1999 Sheep and goat husbandry. In Guide for the Care and Use of Agricultural Animals in Agricultural Research and Teaching, First Revised Edition, pp 6771. Savoy, Illinois: Federation of Animal Science Societies.

Ford SP, Nijland MJ, Miller MM, Hess BW \& Nathanielsz PW 2006 Maternal undernutrition advanced placentomal type, in association with increased placentomal size, and cotyledonary (COT) blood flow. Journal of the Society for Gynecologic Investigation.
Supplement $13212 \mathrm{~A}$.

Ford SP, Vonnahme KA, Drumhiller MC, Reynolds LP, Nijland MJ \& Nathanielsz PW 2004 Arteriolar density and capillary volume increase as placentomes advance from type $A$ through type $D$ developmental stages. Proceedings Society for the Study of Reproduction pp 509.

Fowden AL \& Hill DJ 2001 Intra-uterine programming of the endocrine pancreas. British Medical Bulletin 60123-142.

Gardner DS, Tingey K, Van Bon BWM, Ozanne SE, Wilson V, Dandrea J, Keisler DH, Stephenson T and Symonds ME 2005 Programming of glucose-insulin metabolism in adult sheep after maternal undernutrition. American Journal of Physiology; Regulatory Integrated Comparative Physiology 289 R947-R954.

Gilbert JS, Lang AL, Grant AR \& Nijland MJ 2005 Maternal nutrient restriction in sheep: hypertension and decreased nephron number in offspring at 9 months of age. Journal of Physiology 565.1 137-147.

Gluckman PD \& Hanson MA 2004 Developmental origins of disease paradigm: a mechanistic and evolutionary perspective. Pediatric Research 56 311-317.

Hales CN \& Ozanne SE 2003 The dangerous road of catch-up growth. Journal of Physiology 547 5-10.

Hawkins P, Steyn C, McGarrigle HH, Calder NA, Saito T, Strarford LL, Noakes DE \& Hansona MA 2000 Cardiovascular and hypothalamic-pituitary-adrenal axis development in late gestation fetal sheep and young lambs following modest maternal nutrient restriction in early gestation. Reproduction, Fertility \& Development 12 443-456.

Heasman L, Clarke L, Stephenson TJ \& Symonds ME 1999 The influence of maternal nutrient restriction in early to min-pregnancy on placental and fetal development in sheep. Proceedings of the Nutrition Society 58 283-288.

Heywood WE, Mian N, Milla PJ \& Lindley KJ 2004 Programming of defective rat pancreatic beta-cell function in offspring from mothers fed a low-protein diet during gestation and the suckling periods. Clinical Science (London) 107 37-45.

Hoet JJ \& Hanson MA 1999 Intrauterine nutrition: its importance during critical periods for cardiovascular and endocrine development. Journal of Physiology 514 617-627.

Knight B, Pennell C, Lye S \& Lunenfeld S 2005 Strain differences in the impact of maternal dietary restriction on fetal growth, pregnancy and postnatal devel- 
opment in mice. Proceedings DOHaD Meeting pp1031.

Kwon H, Ford SP, Bazer FW, Spencer TE, Nathanielsz PW, Nijland MJ, Hess BW \& Wu G 2004 Maternal nutrient restriction reduces concentrations of amino acids and polyamines in ovine maternal and fetal plasma and fetal fluids. Biology of Reproduction 71 901-908.

Latini G, De Mitri B, Del Vecchio A, Chitano G, De Felice C \& Zetterstrom R 2004 Foetal growth of kidneys, liver and spleen in intrauterine growth restriction: "programming" causing "metabolic syndrome" in adult age. ACTA Paediatrica 93 1559-1560.

Lopes Da Costa C, Sampaio De Freitas M \& Sanchez Moura A 2004 Insulin secretion and GLUT-2 expression in undernurished neonate rats. Journal of Nutrition \& Biochemistry 15 236-241.

Matthews SG, Owen D, Banjanin S \& Andrews MH 2002 Glucocorticoids, hypothalamo-pituitary-adrenal (HPA) development, and life after birth. Endocrine Research 28 709-718.

Moss TJ, Sloboda DM, Gurrin LC, Harding R, Challis JR \& Newnham JP 2001 Programming effects in sheep of prenatal growth restriction and glucocorticoid exposure. American Journal of Physiology; Regulatory Integrated Comparative Physiology 281 R960R970.

NRC 1985 Nutrient requirements and signs of deficiency. In Nutrient Requirements of Sheep, edn 6, pp 2-25. The National Academies Press, Washington, DC.

Oliver MH, Hawkins P, Breier BH, Van Zijl PL, Sargison SA \& Harding JE 2001 Maternal undernutrition during the periconceptual period increases plasma taurine levels and insulin response to glucose but not arginine in the late gestational fetal sheep. Endocrinology 142 4576-4579.

Osgerby JC, Gadd TS \& Wathes DC 1999 Expression of insulin-like growth factor binding protein-1 (IGFBP1) mRNA in the ovine uterus throughout the estrous cycle and early pregnancy. Journal of Endocrinology 162 279-287.

Osgerby JC, Wathes DC, Howard D \& Gadd TS 2002 The effect of maternal undernutrition on ovine fetal growth. Journal of Endocrinology 173 131-141.
Osgerby JC, Wathes DC, Howard D, \& Gadd TS 2004 The effect of maternal undernutrition on the placental growth trajectory and the uterine insulin-like growth factor axis in the pregnant ewe. Journal of Endocrinology 182 89-103.

Reaven GM 2005 Why syndrome X? From Harold Himsworth to the Insulin Resistence Syndrome. Cell Metabolism 1 9-14.

Schwitzgebel VM 2001 Programming of the pancreas. Molecular \& Cellular Endocrinology 185 99-108.

Simmons RA, Templeton LJ \& Gertz SJ 2001 Intrauterine growth retardation leads to the development of type 2 diabetes in the rat. Diabetes $502279-2286$.

Stocker CJ, Arch JRS \& Cawthorne MA 2005 Fetal origins of insulin resistence and obesity. Proceedings of the Nutrition Society 64 143-151.

Vatnick, I, Schoknecht, PA, Darrigrand, R \& Bell, AW 1991. Growth and metabolism of the placenta after unilateral fetectomy in twin pregnant ewes. Journal of Developmental Physiology 15 351-356.

Vonnahme KA, Hess BW, Hansen TR, McCormick RJ, Rule DC, Moss GE, Murdoch WJ, Nijland MJ, Skinner DC, Nathanielsz PW \& Ford SP 2003 Maternal undernutrition from early- to mid-gestation leads to growth retardation, cardiac ventricular hypertrophy, and increased liver weight in the fetal sheep. Biology of Reproduction 69 133-140.

Vonnahme KA, Hess BW, Nijland MJ, Nathanielsz PW \& Ford SP 2006 Placentomal differentiation may compensate for nutrient restriction in ewes adapted to harsh range conditions. Journal of Animal Science 84 3451-3459.

Wolffe JE, Dobbie PM \& Petric DR 1989 Anabolic effects of insulin in growing lambs. Quarterly Journal of Experimental Physiology 74 451-463.

Wu G, Shi W, Spencer TE, Hess BW, Nathanielsz PW \& Ford SP 2005 Production system under which ewes are selected alters nutrient availability to the fetus in response to early pregnancy undernutrition. Proceedings American Society of Animal Science, Cincinnati, $\mathrm{OH}$, p.297. 